\title{
Implementation of Outcome Based Education: A Beginning
}

\author{
Priya Sawant ${ }^{1 *}$ \\ ${ }^{1}$ Department of Telecommunication Engineering, \\ Marathwada Mitra Mandal's College Of Engineering \\ „S.No 18, Hillside, Karvenagar, \\ Pune 411052 \\ 1hod.etc@mmcoe.edu..in
}

\begin{abstract}
Ever since Outcome Based Education (OBE) has been made mandatory for accreditation of an engineering programme by National Board of Accreditation (NBA), many engineering institutes have adopted OBE. OBE model of accreditation focuses on objectives and outcomes of an engineering programme. It requires evidences of attainment of the predefined outcomes. The basic difference between OBE and traditional learning is that OBE is more 'Learner Centric' and focuses on what a student has learnt rather than what the faculty teaches. 'Learner Centric' model places the student at the centre of the learning process. At the heart of OBE are the Graduate Attributes. Marathwada Mitra Mandal's College of Engineering (MMCOE) is implementing OBE in all its undergraduate programmes since semester-II of academic year 2014-2015. This paper is an attempt to put forth the initiatives taken by MMCOE to adopt OBE philosophy. A Microsoft Excel-based system is used for computation of CO-PO attainment.The system takes into account both direct and indirect tools of assessment.
\end{abstract}

Keywords: Outcome Based Education, Graduate Attributes, Program Outcomes, Course Outcomes, Attainment, Microsoft Excel-based system, Digital Course File.

\footnotetext{
Priya Sawant ${ }^{1^{*}}$

${ }^{1}$ Department of Telecommunication Engineering, Marathwada Mitra Mandal's College Of Engineering „S.No 18, Hillside, Karvenagar, Pune 411052

1hod.etc@mmcoe.edu..in
}

\section{INTRODUCTION}

India became a permanent (signatory) member of Washington Accord on June 13, 2014 [5]. The Washington Accord is an international accreditation agreement for professional engineering academic degrees. Graduates of accredited programs in any of the signatory countries are recognized by the other signatory countries as having met the academic requirements for entry to the practice of engineering. The Washington Accord covers undergraduate engineering degrees under Outcome Based Education [5].

While the earlier accreditation model viz. input-output model focused on direct prescriptions of curriculum and faculty composition, it stifled innovation and creativity in the curriculum [5]. There has been a paradigm shift in the accreditation model now. In the learner-centred paradigm, the student is expected to be an active participant in the education process. Contrary to the traditional methods of teaching, in OBE model the faculty is a mere facilitator or mediator of the learning process as opposed to an instructor who disseminates truth [6]. Students are encouraged to take greater responsibility for their learning outcomes.

$\mathrm{OBE}$ is an approach to education wherein the curriculum is designed to achieve the predefined learning outcomes. OBE model of accreditation focuses on objectives and outcomes of an engineering programme. OBE starts with a clear picture of what a student should be able to do, design the curriculum, teaching-learning process and assessment to ensure that the outcomes are attained. OBE model facilitates Continuous Quality Improvement (CQI). Concept of OBE is illustrated in Fig.1. The figure is adapted from [5].

At the heart of OBE are the Graduate Attributes [10]. The competencies that a graduate of a program should have are called Graduate Attributes. The attributes a graduating engineer should have are generally defined by the accreditation agency for engineering and technical education, namely, the National Board of Accreditation (NBA) in India. The Graduate Attributes, also referred to as Program Outcomes, as defined by NBA are based on the 
Program Outcomes stated in Washington Accord [7]. Graduate Attributes are referred to as Program Outcomes by Washington Accord [5].The Graduate Attributes of engineering programs as identified by NBA (January 2013) are [10]:

1. Engineering knowledge

2. Problem analysis

3. Design/development of solutions

4. Conduct investigations of complex problems

5. Modern tool usage

6. The engineer and society

7. Environment and sustainability

8. Ethics

9. Individual and team work

10. Communication

11. Project management and finance

12. Life-long learning

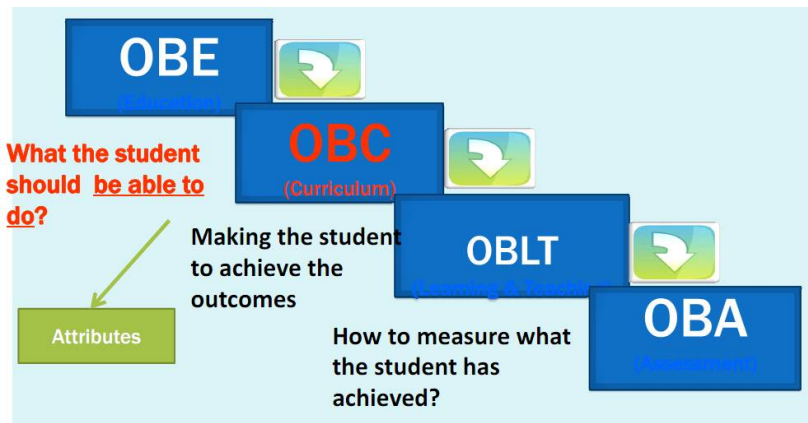

Fig.1 Outcome Based Education [5]

\section{OBE Structure}

The key elements of OBE shown in Fig.2 [5] are as follows:

Vision: It is a futuristic statement that the institution or department would like to achieve over a long period of time [10].

Mission: Mission statements are essentially the means by which the institution or department proposes to move towards its vision [10].

Programme Educational Objectives (PEOs): Are broad statements that describe the career and professional accomplishments that the program is preparing the graduates to achieve [10].

Program Outcomes (POs): Are narrower statements. They describe what students are expected to know and will be able to do by the time of graduation [10]. They relate to the knowledge, skills and behaviour of students as they progress through their graduation program and upon graduation. Program outcomes must align with and reflect all graduate attributes

Course Outcomes (COs): Course Outcome statements are more specific to a particular course. They describe what students are expected to know and will be able to do at the end of each course. COs are the basic building block of the
OBE structure. They are mapped to POs in a CO-PO mapping matrix. The CO-PO correlation is to be weighed by a correlation factor, where the correlation levels are:

1: Slightly 2: Moderately 3: Substantially

The cell is to be left blank if there is no correlation [7].

Teaching-Learning Process:

Once the POs and particularly COs are defined, delivery method is planned to ensure effective student learning. The teaching-learning process should ensure that the student acquires the knowledge and skills as stated by the POs \& COs.

Assessment: Even as, 'student-centric' approach encourages students to take greater responsibility for their learning outcomes, it is imperative that proper assessment

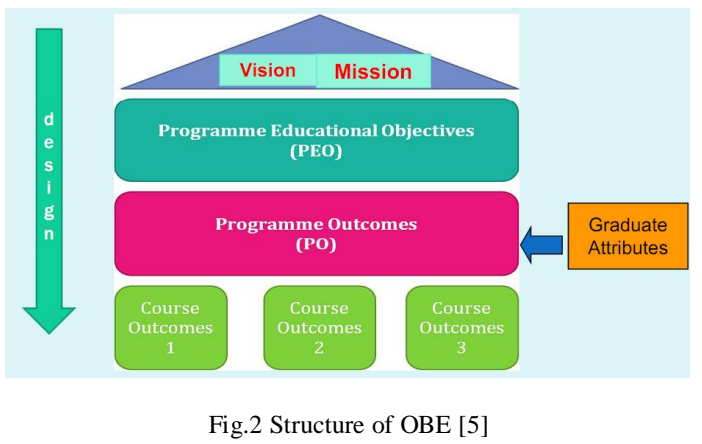

is done to ascertain that the student has attained the stated outcomes. Assessment is one or more processes to identify, collect, and prepare data to evaluate the attainment of COs, POs and PEOs. Assessment of PEOs attainment is typically done a few years after graduation. POs are assessed during graduation and upon graduation, while attainment of COs is done at the end of a course [10].

Assessment can be broadly classified into two types formative assessment and summative assessment [4]. In formative approach assessment is done in 'real-time' during the teaching-learning process. Assessment done by conducting a test or exam at a specific period of time is summative assessment.

Further, assessment can be indirect assessment and direct assessment. While indirect assessment aids in ascertaining opinions/self reports, direct assessment uses measurable performance indicators of students. In indirect assessment methods faculty has to infer actual student skills, abilities, knowledge, and values from sources other than observable, direct evidence. This involves students self-reporting their learning or progress. Much emphasis is laid on the use of rubrics in indirect assessment methods. A Rubric is a method for quantifying students' achievement of learning outcomes that represent higher levels of thinking, application of skills, and observable, though not immediately measurable, aspects of learning. A rubric is a table that lists descriptors for the components and levels of achievement for a task, performance, or set of behaviours [9].

\section{JEËr}


Evaluation \& Continual Quality Improvement (CQI): The OBE process is incomplete without evaluation of the assessment done. Evaluation is one or more processes done by the evaluation team for interpreting the data and evidence accumulated through assessment practices[10]. Evaluation determines the extent to which PEOs, POs and COs are achieved. The next step to evaluation is to identify the lacunae and formulate an action plan to improve the programme holistically. This forms the basis of Continual Quality Improvement (CQI).

This paper presents the initiatives taken by Marathwada Mitra Mandal's College of Engineering (MMCOE) to adopt OBE philosophy. The paper is structured as follows. Section II presents the transition process including the computation of CO-PO attainment. Section III is the concluding section of the paper

\section{Transitioning to OBE}

Academics has always been the major focal point in Marathwada Mitra Mandal's College of Engineering since its inception in 2006. Well defined academic policies, expert sessions by industry experts and senior academicians, use of ICT to ensure effective delivery of quality teaching and knowledge dissemination are a hallmark of MMCOE. A decision to get our programs accredited by NBA triggered an interest in OBE. A study of OBE philosophy made us realize that our pedagogy was more exam driven and subconsciously encouraged rote learning.

Transition to OBE started in semester II of academic year 2014-2015. This transition started with making appropriate changes in our academic policies and teaching-learning process. To facilitate uniform and standard implementation of OBE various committees have been formed at the department and institute level. The role of the department level committees shall be discussed throughout this paper as and when relevant.

Vision and Mission of Institute and Department:

At the outset, Vision and Mission of the institute was defined based on the recommendations of the Governing Body (GB), Internal Quality Assessment Committee (IQAC) and guidelines from the Academic Monitoring Committee (AMC). The various departments then established their individual vision and mission in line with the institute's vision and mission. The department vision and mission was defined based on recommendations of the Department Advisory Board (DAB) and stakeholders comprising of industry, alumni, students, parents and staff. Industrial Advisory Board (IAB), alumni association, parent association and student focus groups represent the above listed stakeholders.

\section{Programme Educational Objectives:}

Opinions of DAB and various stakeholders were sought to define and formulate the PEOs. Emphasis is on consistency of PEOs with the institute mission, the department mission and the Graduate Attributes defined by NBA.

Examples of Programme Educational Objectives:

- To create a strong base in mathematics, science and engineering fundamentals required to solve Electronics and Telecommunication problems.
- To create a strong base in mathematics, science and engineering fundamentals required to solve Electronics and Telecommunication problems.

- To up skill students with applied engineering knowledge so as to comprehend, analyze, design and create modern products for real life complex engineering problems in the field of Electronics and Telecommunication.

- To impart good communication skills, team work and leadership qualities to students and create ethical professionals concerned about the impact of engineering solutions on environment and society.

\section{Program Outcomes (POs)}

As per NBA guidelines and SAR 2015 format, POs have been published by NBA in Annexure I [7]. While PO1 to PO5 focus on technical proficiency and are domainoriented, PO6 to PO12 are aimed at developing professional skills of a graduate. The POs are aligned to the Graduate Attributes. Mapping between the POs \& Graduate Attributes shows a one-to-one correspondence between them. In addition to POs, Program Specific Outcomes can also be defined.

\section{Electronics and Telecommunication Engineering} curriculum

As per the structure of OBE the next step is to design curriculum. Marathwada Mitra Mandal's College of Engineering is affiliated to Savitribai Phule Pune University and follows the curriculum defined by the university. The curriculum comprises of broad curricular components that contribute towards the achievement of the Programme Educational Objectives. The curriculum is divided into domains as follows: Engineering Sciences, Core Engineering, Breadth, Electives - core and open, Project and Humanities. The basic module in every course is called a unit. A course is typically comprised of six units. Senior faculty are deputed as domain co-ordinators for various domains. The domain co-ordinators formulate guidelines to define and redefine (if needed) course objectives and course outcomes and guide the respective course coordinators and course faculty.

Hence, the next step is defining course outcomes in line with the POs. The COs should be assessable and measureable. A helpful and frequently used resource when writing course outcomes is Bloom's Taxonomy.

\section{Bloom's Taxonomy}

Bloom's Taxonomy focuses on the classical 'knowledge, attitude, skills' structure of learning and evaluation method. It emphasises on 'mastering' a course and promotes higher levels of thinking rather than 'rote' learning. Through its' three domains, cognitive, affective and psychomotor, Blooms Taxonomy covers all human aspects as follows:

- Cognitive - knowledge and intellect- 'think'

- Affective - attitude and beliefs- 'feel'

- Psychmotor - ability to effectively use physical and bodily skills- 'do'

Readers are referred to [11] for a detailed explanation of Bloom's Taxonomy. 


\section{Course Outcomes (COs):}

Example - Course outcomes of the course 'Digital Signal Processing' for Third Year Engineering Undergraduate program:

On completion of this course the student should be able to: CO1: Apply sampling theorem, analyse recovery of signals from signal samples and determine aliasing.

CO2: To understand the use of different transforms and analyse the discrete time signals and systems.

CO2a: Apply Fourier knowledge of Mathematics to

discrete time signals to obtain the frequency domain representation

$\mathrm{CO} 2 \mathrm{~b}$ : Apply knowledge of Z-transform to analyse digital systems with respect to pole- zero plot, stability, linearity, causality, impulse response and frequency response CO3: To design and realize IIR and FIR filters and analyze filters with respect to filter order, transition width, passband/stop band ripple, stability, causality and filter response

CO4: To calibrate and resolve different frequencies existing in any signal

CO5:To design and implement multistage sampling rate converter

CO6: To use modern tools like MATLAB, Code Composer Studio and DSP Processor and develop MATLAB code relevant to DSP curriculum

CO7: To engage in independent learning, and work as a member of a team, use ICT for effective presentation on a topic relevant to DSP.

Delivery of course content:

Prior to commencement of the semester each course faculty prepares a session plan, lesson plan, CO-PO mapping matrix, lecture notes, list of experiments to be performed in the laboratory, laboratory manual and handouts. The course contents are uploaded on Google apps and are shared with the students taking that particular course. Effective use of power point presentations, chalk-talk teaching, video clippings of National Programme on Technology Enhanced Learning (NPTEL) lectures, lectures by industry experts and senior academicians, industrial visits, webinars etc. ensure holistic delivery of the course contents. Curricular gaps are identified in consultation with department advisory board, industrial advisory board and alumni and bridged through expert sessions, video clippings of NPTEL lectures, industrial visits, webinars and add-on workshops.

\section{Assessment of attainment of POs, COs and PEOs:}

The DAB formulates guidelines regarding direct and indirect assessment tools to evaluate attainment of PEOs, POs and COs by collaborating with programme assessment committee, and domain coordinators. The programme assessment committee designs and revises indirect assessment tools viz. alumni, graduate exit, employer, parents and industry survey forms.

Assessment of attainment of COs is done at the end of a course, which is typically at the end of the semester in a semester- based academic pattern. CO assessment for every course is done at both, individual student level and class (typically 60-75 students) level. This helps in identifying the under-performers and planning appropriate remedial measures. Both direct and indirect assessment tools are used. Affiliating university focuses on summative assessment. As COs are mapped to POs through the CO$\mathrm{PO}$ matrix along with correlation factor, computation of $\mathrm{CO}$ attainment also gives PO attainment achieved through a course.

\section{Direct Assessment Methods: Tools and attainment}

1. Unit Test - CO attainment

2. Tutorials - $\mathrm{CO}$ attainment

3. Quiz - CO attainment

4. Assignments - $\mathrm{CO}$ attainment

5. Laboratory performance - $\mathrm{CO}$ attainment

6. Presentations - $\mathrm{CO}$ attainment

7. University exams- In-semester and End-semester - CO attainment

Indirect Assessment Methods: Tools and attainment

1. Alumni survey - PEO attainment

2. Graduate exit survey - PEO attainment

3. Course outcome survey - $\mathrm{CO}$ attainment

4. Employer survey - PEO attainment

Every question, quiz and laboratory performance is mapped to the $\mathrm{CO}$ it addressed. Assignment and test questions are designed using Bloom's Taxonomy.

A MS-Excel-based system called Digital Course File (DCF) is developed for computation of CO-PO attainment for each student and class average. Colour coding is effectively used in the DCF to differentiate between underperformers and students who have satisfactorily met the target.

\section{ICTs used for collecting data for assessment:}

Quizzes and course outcome survey forms were designed using Google forms. Fig.3 is a snapshot of Google forms for course end survey.

\section{CO -PO attainment method:}

The digital course file includes the following data:

1. Syllabus of the course - Unit wise

2. Mapping of various units to COs with correlation factor

3. Mapping of COs to POs with correlation factor

4. Mapping of POs with PEOs with correlation factor

5. Separate Excel sheets for marks entry of different assessment tools, viz. test, assignments, etc. with $\mathrm{CO}$ mapping. Fig. 4 is a snapshot of marks entry of unit test 1 with questions mapped to units

6. Data of various surveys. Fig.5 illustrates the mapping of COs with course end survey questions

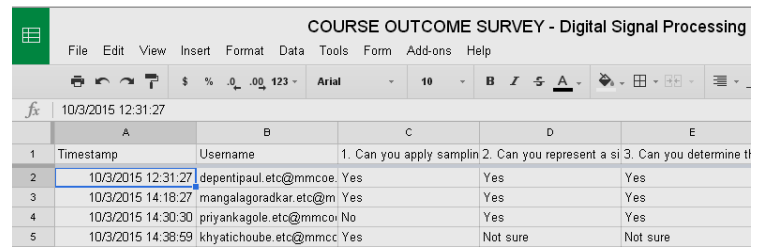

Fig.3 Use of Google forms for course end survey 


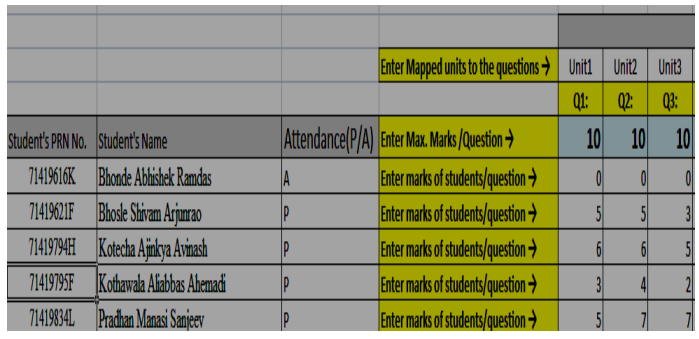

Fig.4 Marks entry of unit test 1 with questions mapped to units

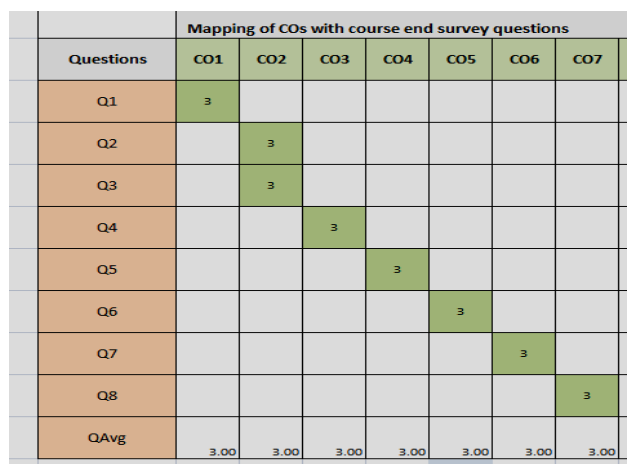

Fig.5 Mapping of COs with course end survey questions

\section{Description of the CO-PO attainment method}

The developed MS-Excel-based system generates report on the attainment of COs and POs for each student and class average. Presently the digital course file is limited to computing the $\mathrm{CO}-\mathrm{PO}$ attainment for individual course.

The mapping of various units of the course syllabus with COs with correlation factor and mapping of COs to POs with correlation factor play an important role in the computation of $\mathrm{CO}-\mathrm{PO}$ attainment.

Correlation factors as specified by NBA in its Self Assessment Report Format are:

1: Slightly 2: Moderately 3: Substantially [7]

Steps of computation of $\mathrm{CO}-\mathrm{PO}$ attainment of class :

1. Based on the CO-PO matrix of the course, ' $\mathrm{CO}_{\text {avg' }}$ ' is computed for every PO. ' $\mathrm{CO}_{\text {avg' }}$ ' is the average approximation of relevant entries. For example, if entries under PO1 for CO1-7 are 1,3,1,1,1,1,1 respectively then attainment of $\mathrm{PO} 1$, that is ' $\mathrm{CO}_{\text {avg }}$ ' is 9/7 is approximately 2. ' $\mathrm{CO}_{\text {avg' }}$ ' for PO1-PO12 is similarly computed. Unitavg and $\mathrm{PO}_{\mathrm{avg}}$ is also computed using the Unit-CO matrix and the PO-PEO matrix respectively.

2. Next COs attained by each student are computed as: (Marks of student*correlation factor of $\mathrm{CO}$ with unit) / Unit ${ }_{\text {avg }}$

3. Next POs attained by each student are computed as: (Marks of student*correlation factor of PO with $\mathrm{CO}$ ) / $\mathrm{CO}_{\mathrm{avg}}$
4. Average COs attained for a course by the class is computed as: (total COs)/(total students in class)

5. Percentage of average $\mathrm{COs}$ is computed as: $\left[(\right.$ average $\left.\mathrm{COs}) /\left(\mathrm{CO}_{\max }\right)\right] * 100 \%$

6. Average POs attained for a course by the class is similarly computed

Fig.6 shows the graph of percentage of average $\mathrm{CO}$ attainment including (Direct Assessment) absenteeism. CO attainment of an under-performer is shown in Fig.7.

\section{Role of indirect assessment tools}

Indirect Assessment Tools comprise of the various survey forms and are also considered for CO-PO attainment. Every question in the course-end survey form is mapped to the relevant course outcome in the digital course file and contributes to the course attainment and hence attainment of program outcomes. Similarly every question in the. alumni, and graduate exit employer, parents and industry survey forms is mapped to the relevant Programme Educational Objective. Once the data is keyed into the digital course file CO-PO attainment is computed

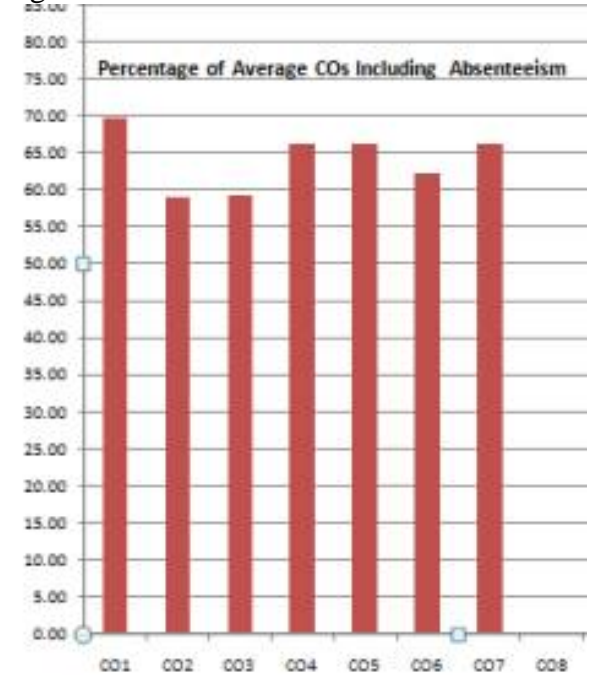

Fig.6 Percentage of average COs including absenteeism (Direct Assessment)

automatically. $80 \%$ weightage is given to direct assessment and $20 \%$ weightage is given to indirect assessment as per recommendations from the department advisory board and programme assessment committee. Total $\mathrm{CO}$ attainment is then computed using Eq.1

Total $\mathrm{CO}$ attainment $=0.8^{*} \mathrm{CO}($ Direct $)+0.2^{*} \mathrm{CO}$ (Indirect)

The author would like to mention that the results shown in this manuscript are relevant only for the course of 'Digital Signal Processing' for Third Year Engineering Undergraduate program for semester I of academic year 
2015-16. Though the digital course file also includes the results of the end-semester exam conducted by the varsity, results in the manuscript demonstrate only the attainment achieved through internal assessment.

\section{Result Analysis and Continuous Quality Improvement}

The programme assessment committee and course faculty analyse the results of the attainment of COs and POs and compute the total attainment of PEOs. It submits a report regarding attainment of PEOs, POs and COs to the DAB, which then reviews the analysis and prepares an action plan to improve student learning. Course faculty is also actively involved in the process of improving the teaching-learning process and continuous quality improvement.

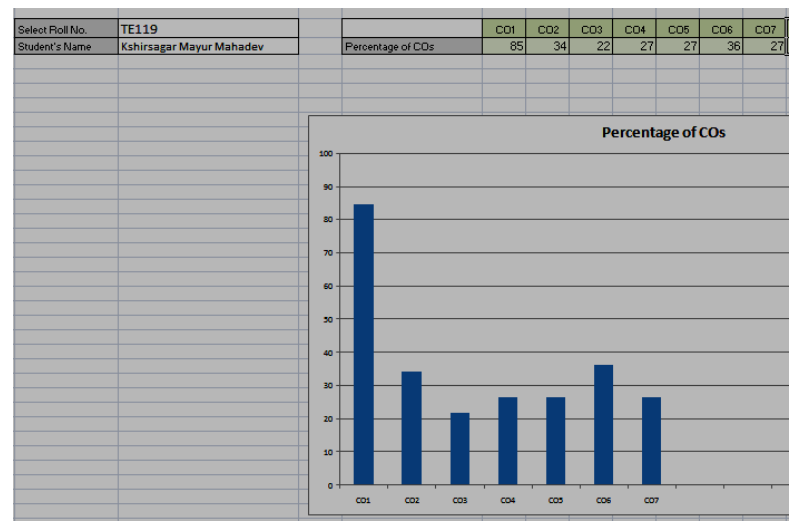

Fig.7 CO attainment of a 'weak' student

Some important observations made during the review process are:

- $\quad$ PO6 and PO8 have not been addressed and will be looked into in the coming semester

- Though results shown here indicate that PO11 has not been addressed, for the course of 'Digital Signal Processing'. PO11 is satisfactorily attained through the courses' Mini Project and Seminar' at third year and 'Project' at the final year

- Though average $\mathrm{CO}$ and PO attainment have met with the set targets $(50 \%)$, the $\mathrm{CO}-\mathrm{PO}$ attainment of some students is very low

- Attainment of CO7 of some students is alarmingly low.

Examples of action plan to overcome the lacunae:

- Emphasis will be on addressing PO6 and PO8 through appropriate activities
- Counselling and conduction of remedial classes and/ or extra tutorial classes for 'weak' students

- Identify the learning styles of students in a class and suitably form groups to conduct activities related to $\mathrm{CO} 7$, so as to ensure that strengths are exploited and weaknesses strengthened

- Incorporate formative assessment so that 'weak' students can be identified effectively

\section{CONCLUSION}

This paper presents the transition process of MMCOE as it moves towards complete implementation of OBE. A major change that was incorporated was the change in internal assessment. Contrary to the earlier policy of internal assessment through unit tests and assignments only, assessments are more frequently done in the form of quizzes, group activities, presentations etc.

Faculty are trying to evaluate the ability of a student to communicate effectively and work in a team through the technical courses in the curriculum.

Results of attainments relevant to the course of 'Digital Signal Processing' are presented in this paper. Process of collecting data and computing attainment of COs of various courses \& thence POs attained through these courses is complete and action plans are made to ensure continuous quality improvement.

Since implementation of OBE started from semester II of academic year 2014-2015, the process is still evolving. In the coming semesters focus would be on addressing the POs aimed at developing professional skills of a graduate. Additionally, Program Specific Outcomes (PSOs) would be defined. Emphasis would be on multidisciplinary 'realworld' problems and enhancing the depth of knowledge. Students would be encouraged and motivated to use collaborative learning techniques and enhance their learning ability.

This process of moving to outcome based education has had a positive impact on the overall teaching - learning process, encouraging the students and faculty to excel.

\section{Acknowledgement}

The author wishes to acknowledge Indo US Collaboration for Engineering Education (IUCEE) for giving valuable insights into OBE through its workshops and webinars. The author would like to acknowledge the contribution of $\mathrm{Mr}$. Sunil Sawant, Proprietor, M J Woods in designing the digital course file for computation of CO-PO attainment.

\section{REFERENCES}

[1] B Kanmani, K Mallikharjuna Babu, “ Continuous Improvements in Teaching-Learning- Process in Outcomes Based Education", Journal of Engineering 
Education Transformations, volume 28, No.2\&3, Oct 2014 \& Jan.2015.

[2] Anala M. R,. Hemavathy R., Shobha G., "Outcome Based Education: An Emprical Approach", Journal of Engineering Education Transformations, volume 28, No.2\&3, Oct 2014 \& Jan.2015.

[3] Mukund V. Kavade, " Assessment and Attainment of Course Outcomes and Program Outcomes", Journal of Engineering Education Transformations, volume 28, No.2\&3, Oct 2014 \& Jan.2015.

[4] Izham Zainal Abidin, Adzly Anuar and Norshah Hafeez Shuaib, "Assessing the attainment of course outcomes (CO) for an engineering course", Proceedings of the $2^{\text {nd }}$ International Conference of Teaching and Learning (ICTL 2009), INTI University College, Malaysia.

[5] Training Text material, 3-day workshop on 'Outcome Based Accreditation' for Evaluators/ Resource Persons, National Board of Accreditation (NBA).

[6] Joe Cuseo, " The Case and Context for LearnerCentered Pedagogy", BlueGrass Community and Technical College

[7] http://nbaind.org/Files/sar-ug-t-ii-final-ver-06.pdf

[8] http://www.nbaind.org/En/1055-learning-resources.aspx

[9] www.santarosa.edu/slo/assets/Methods-ofAssessment.pdf

[10] http://nbaind.org

[11] Anderson,L. And Krathwohl,D.(2001. "A Taxanomy for Learning, Teaching and Assessing : A revision of Blooms' Taxanomy of Educational Objectives". New York: Longman 